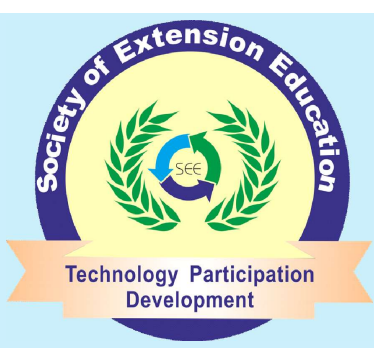

Research Article

\section{Indian Research Journal of Extension Education}

ISSN: 0972-2181 (Print), 0976-1071 (Online)

NAAS Rating : 5.22

Journal homepage: seea.org.in

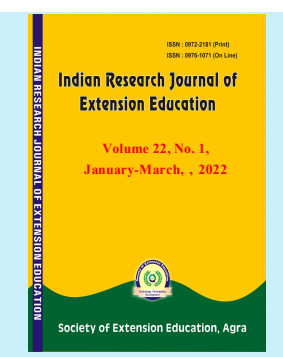

https://doi.org/10.54986/irjee/2022/jan_mar/60-65

\title{
Institutional Factors Driving Participation of Marginalized Section(s) in Livestock Extension Programs in Tamil Nadu
}

\author{
Jothilakshmi. $\mathbf{M}^{1}$, N. Narmatha ${ }^{2}$, B. Mohan $^{3}$, N.Akila ${ }^{4}$ and V. Senthilkumar ${ }^{5}$
}

1. Asstt. Prof., 2. Dean, 3. Controller of Examinations, 4. Professor and Head, 5. Asstt. Prof. and Head, Veterinary College and Research Institute, Namakkal, Tamil Nadu Veterinary and Animal Sciences University, India Corresponding author e-mail :drjothi80@gmail.com

Revised Paper Received on October 22, 2021, Accepted on November 28, 2021, Published Online on January 01,2022

\begin{abstract}
Livestock plays an important role in livelihood of small and marginal farmers with 5.47 per cent of state GDP (Gross domestic product) and one of the primary sources of employment to marginalized section(s) of rural Tamil Nadu. This study was undertaken to identify the factors driving participation of marginalized section(s) in livestock extension programs in Tamil Nadu. The study was conducted in Tamil Nadu from February 2020 to September 2021 at Tamil Nadu Veterinary and Animal Sciences University, India. Primary data was collected from the selected sample of 23 extension centres using structured questionnaire in google form and secondary data was collected from the Directorate of Extension Education, TANUVAS for the period of 2017 to 2019. Descriptive statistics (frequency, percentage, chi-square and Mann-Whitney $U$ test) were used to analyze the data. The results revealed that better staff availability in the centre and higher proportion of off-campus programs significantly influenced the inclusiveness of marginalised sections in overall extension programmes. Furthermore, improving transport facilities through mobility innovations such as pooling of transport and hiring models during on-campus programmes may facilitate better participation / inclusion level of marginalised sections.
\end{abstract}

Key words : Access to extension; Inclusiveness; Livestock extension; Marginalised section; Schedule tribe.

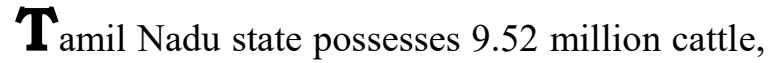
14.4 million small ruminants and 120 million poultry population (Livestock census, 2017). On comparing with previous livestock census expect buffalo and sheep population, other livestock has been substantially increased. Further, apart from commercial poultry (layer and broilers) sector, other livestock enterprises are mostly operated under smallholder farming system. The landless, small and marginal farmers own majority of cattle, small ruminants and backyard poultry. Dairying contributes around 21 to 28 per cent of householder's income in various crop-livestock systems of Tamil Nadu
(Thirunavukkarasu et al., 2019). Further, livestock activities act as one of the primary sources of employment to marginalised section(s) of rural Tamil Nadu. The distribution of livestock wealth is more egalitarian compared to land (GoTN, 2020) and the lower caste(s) own considerable proportion of livestock (Thirunavukkarasu et al., 2021) and women play a predominate role in livestock farming activities (Narmatha et al., 2009 and Jothilakshmi et al., 2014). The above socially and economically marginalised section(s) activities in livestock have placed Tamil Nadu as one among the top 10 milk producing state of India. 
Added, during 2019-20 livestock has accounted to 5.21 per cent of state GDP (Gross domestic product) and nearly 42 per cent of agriculture gross domestic product (GoTN, 2020). The farmers associated with smallholder livestock primarily access livestock extension services from state animal husbandry and dairy cooperatives even though post - liberalisation era has paved for multiple agencies (Jothilakshmi et al., 2011). Added to the above, state agriculture / veterinary university too provide livestock extension services through Krishi Vigyan Kendra, Veterinary University Trainings and Research Centre (VUTRCs) and Farmers Training Centre (FTC). These public sector organisation(s) in the state has been limited with human resources, budget and other resources (Ravikumar et al., 2006 and Chander et al., 2010). These above factors restricted farmer's accesses to extension system. In specific, the marginalised section(s) such as women and Schedule caste /Schedule tribes (SC/ST) have poor access to extension services in India (Raghunathan et al., 2018 and Krishna et al., 2019). Dethier \& Effenberger (2012) through narrative literature review observed that institutional factors of organisations too played a significant role in delivery of / access to extension services in developing countries. These, necessitates to understand the role of institutional factors influencing the marginalised section to access livestock extension services. Thus, this study makes an attempt to study the association among institutional variables with women and marginalised section's access to livestock extension services in Tamil Nadu.

\section{METHODOLOGY}

To test the above hypothesis, this research was carried out in 23 extension (VUTRCs and FTCs) centres /constituent unit of Directorate of Extension Education of Tamil Nadu Veterinary and Animal Sciences University (TANUVAS) distributed across the state. Selected primary institutional data from above centres were collected through questionnaire method using Google form. Extension programs/activities carried out by the above centres (secondary data) were collected from Directorate of Extension Education, TANUVAS. The secondary data were collected for the period of 2017 to 2019 during 2020-21. Researchers focussed on the primary livestock commodities namely dairy, small ruminant and backyard poultry training programmes to estimate access / inclusion level in this study. The descriptive analysis was used to have understanding on pattern and distribution of beneficiaries. In addition, the researchers converted inclusion data (share of marginalised sections) of 23 extension centres into low, medium and high (from interval to ordinal level of measurement) using cumulative square root frequency (Dalenius and Hodges method) for chi-square and Mann-whitney u test analysis. Statistical package for social science (SPSS) was used for statistical analysis.

\section{RESULTS AND DISCUSSION}

The study found that livestock extension centres had average operational period of more than 24 years ( 24.13 years). Each centre had sanctioned post of three technical staff, one to two non - teaching and three supporting staff. The majority of technical staff were specialised in Livestock production followed by Health / Para clinics and Extension. The extension programs were delivered both at campus of extension centre as well as outside the campus as off-campus programs. These centres on an average organised 1481 extension programs per year with an overall average participation of 45574 farmers. Nearing four-fifth (79\%) of the above extension programmes were on dairy, small ruminant and backyard poultry. Out of these three-fifth beneficiaries was attended off-campus mode of programs. The participants of on-campus programs were mostly on preference based and while off-campus, participants were made to attend the programme to avail benefits of state/central government subsidised livestock

Table 1. Extent of marginalized sections participation in selective livestock extension programs

\begin{tabular}{lccccccc}
\hline \multirow{2}{*}{ Year } & \multicolumn{2}{c}{ Over all extension programmes } & \multicolumn{2}{c}{ On-campus } & \multicolumn{2}{c}{ Off-campus } \\
& No. & Women $(\%)$ & SC/ST $(\%)$ & Women $(\%)$ & SC/ST $(\%)$ & Women $(\%)$ & SC/ST $(\%)$ \\
\hline 2017 & 31013 & 42 & 24 & 20 & 19 & 66 & 29 \\
2018 & 29041 & 51 & 26 & 26 & 19 & 75 & 34 \\
2019 & 47467 & 67 & 38 & 24 & 22 & 80 & 43 \\
Average & 35840 & 53 & 29 & 23 & 20 & 74 & 35 \\
\hline
\end{tabular}


Table 2. Association between selected institutional variables and participation level of marginalized section(s) in overall livestock extension programs

\begin{tabular}{lccc}
\hline Name of the variable & Level of measurement & DF & Kruskal-wallis $/ \chi^{2}$ value \\
\hline Women inclusion in overall group based extension programs & & \\
Operational years & Continuous & 2 & 1.61 \\
Technical staff availability & Continuous & 2 & $8.37^{*}$ \\
Non-technical staff availability & Continuous & 2 & $7.93^{*}$ \\
Trainer(s) training & Continuous & 2 & 0.75 \\
Receipt of external fund & Continuous & 2 & 0.01 \\
Mass media engagement for awareness & Categorical & 4 & 6.41 \\
Engagement with social media & Categorical & 2 & 3.45 \\
Availability of women technical staff & Categorical & 2 & 0.53 \\
Mode of group based extension program & Categorical & 4 & $12.39^{* *}$ \\
SC/ST inclusion in overall group based extension programs & & \\
Operational years & Continuous & 2 & 1.27 \\
Vacancy of technical staff & Continuous & 2 & $3.72 @$ \\
Vacancy of non-technical staff & Continuous & 2 & 0.77 \\
Trainer(s) training & Continuous & 2 & 2.10 \\
Receipt of external fund & Continuous & 2 & 3.12 \\
Mass media engagement for awareness & Categorical & 4 & 2.92 \\
Engagement with social media & Categorical & 2 & 1.78 \\
Mode of group based extension program & Categorical & 4 & 2.31 \\
\hline
\end{tabular}

** Significant at 1 per cent level * Significant at 5 per cent level @ Significant at 15 per cent level

Table 3. Association between selected institutional variables and participation level of marginalised section(s) in oncampus livestock extension programs

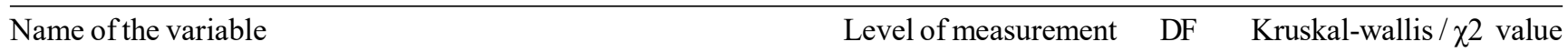

Women inclusion in group based on-campus extension programs

Operational years

Technical staff availability

Continuous

1.71

Non-technical staff availability

Continuous

2.52

Trainer(s) training

Continuous

0.93

Receipt of external fund

Continuous

3.61

Mass media engagement for awareness

Continuous

0.80

Engagement with social media

Categorical

3.56

Categorical

0.15

Availability of women technical staff

Categorical

0.63

Transport facilities available in the centre

Categorical

$8.17^{* *}$

SC/ST inclusion in group based on-campus extension programs

Operational years

Continuous $\quad 2 \quad 2.60$

Technical staff availability

Continuous

3.26

Non-technical staff availability

Continuous

Trainer(s) training

Continuous

Receipt of external fund

Continuous

Mass media engagement for awareness

Categorical

Engagement with social media

Categorical

Availability of women technical staff

Categorical

Transport facilities available in the centre

Categorical

$7.67^{*}$

** Significant at 1 per cent level *Significant at 10 per cent level 
schemes. The overall extension programmes on dairy, small ruminant and backyard poultry had average participants of 35840 per annum. In this, marginalized sections, women and SC/ST participation were accounted to 53 per cent and 29 per cent respectively (Table 1). The participation of SC/ST is in line with the observations of Prasad and Kushwaha (2015). Further, the participation of women and SC/ST in on-campus and off-campus livestock extension programs had explicit variation (Table 1). Training programme participation increase knowledge, improve skill and help to empower marginalised section (Safi and Devi, 2021).

This was obvious from Table 2, the availability of technical staff and non-technical staff (number of mandays) has association with participation of women farmers in livestock extension programmes of centres (Table 2). The centres with better staff position had increased inclusion of women in their programs and vice versa. The man-power determines the performance of extension system was also reported by Mamun-urRashid et al. (2017) and Nandi and Nedumaran (2019). Manpower based extension has been the primary vehicle for engagement with farmers low literacy and had long held and strong belief system which always defied the behaviour change interventions, face to face interface between the extension functionary and the farmer was more credible and effective may be the reason for this.

In addition, the mode of training had highly significant (at $1 \%$ level) association with participation of women in overall livestock extension programs. The centres with higher proportionate of off-campus programs had better participation of women farmers. Cultural reasons, conveyance and mobility issues affects the women's access to extension programs (Abebe et al., 2019 and Atsbeha et al., 2021). These issues were addressed to certain extent when higher proportionate of off-campus programs are arranged at farmers' neighbourhood and women participation in off- campus training programmes was of 74 per cent. This is in line with Bashir et al. (2017) and Anthakumari et al. (2021) Thus, increased staff availability directly relates with mobility and organise a greater number of off-campus programs resulting in higher participation of women.

While, the association between availability of technical staff and participation of SC/ST in livestock extension programs was significant at 15 per cent level only and mode of training had no significant association with inclusion of SC/ST in livestock extension programs. This requires a further study with other related

Table 4. Association between selected institutional variables and participation level of marginalised section(s) in off-campus livestock extension program

\begin{tabular}{|c|c|c|c|}
\hline Name of the variable & Level of measurement & $\mathrm{DF}$ & Kruskal-wallis / $\mathrm{x} 2$ value \\
\hline \multicolumn{4}{|c|}{ Women inclusion in group based off-campus extension programs } \\
\hline Operational years & Continuous & 2 & 0.50 \\
\hline Technical staff availability & Continuous & 2 & 1.41 \\
\hline Non-technical staff availability & Continuous & 2 & 0.98 \\
\hline Trainer(s) training & Continuous & 2 & 2.53 \\
\hline Receipt of external fund & Continuous & 2 & 2.14 \\
\hline Mass media engagement for awareness & Categorical & 4 & 6.06 \\
\hline Engagement with social media & Categorical & 2 & 3.99 \\
\hline Availability of women technical staff & Categorical & 2 & 2.23 \\
\hline \multicolumn{4}{|c|}{ SC/ST inclusion in group based off-campus extension programs } \\
\hline Operational years & Continuous & 2 & 0.99 \\
\hline Technical staff availability & Continuous & 2 & 4.10 \\
\hline Non-technical staff availability & Continuous & 2 & 1.56 \\
\hline Trainer(s) training & Continuous & 2 & 4.35 \\
\hline Receipt of external fund & Continuous & 2 & 0.21 \\
\hline Mass media engagement for awareness & Categorical & 4 & 5.30 \\
\hline Engagement with social media & Categorical & 2 & 0.83 \\
\hline Availability of women technical staff & Categorical & 2 & 1.13 \\
\hline
\end{tabular}


institutional factors for more inclusion of SC/ST in livestock extension programmes.

In case of on-campus programs (Table 3), transport facilities available in the centre was significant at 1 per cent level in inclusion of women in on-campus programs and inclusion of SC/ST was significant at 10 per cent level. The centres with limited public transport connectivity had lesser inclusion of women and SC/ST in livestock extension programmes. Transport facilities was one of the critical factors to access extension centres in developing countries has also observed by Berhane et al. (2018) Thus, the centres located in remote place (poor road / public transport connectivity) demands personal mobility solutions such as twowheeler to avail livestock extension services. While other related institutional variables had no association with the participation of marginalised section, women and SC/ST. None of the institutional variables had any significant association with inclusion of either women or SC/ST sections in off-campus programs of extension centers (Table.4). The variation in inclusion level of women and SC/ST in off-campus programs among centers were not explained by the listed institutional variables and other explanatory factors needs to be studied.

\section{CONCLUSION}

The study found that better technical and nontechnical staff availability in the extension centres and higher proportion of off- campus programs significantly influence the participation of women and SC/ST sections in overall extension programmes. Thus, increasing the human resources availability and filling the existing vacancies may pave way for better access to livestock extension services by marginalised sections. Off-campus approach has provided better dividends in terms of inclusiveness. Hence, off-campus mode of livestock extension services of centres can be continued / increased with necessary financial, human and other resources. Furthermore, improving transport facilities through mobility innovations such as pooling of transport and hiring models during on-campus programmes may facilitate better inclusion of marginalised sections in livestock extension programmes of extension centres and incentivizes them to take up of recommended technologies will also not only help to improve their livelihood but also to improve their nutritional security.

\section{ACKNOWLEDGEMENT}

The authors are grateful for the support provided by the Directorate of Extension Education, Tamil Nadu Veterinary and Animal Sciences University (TANUVAS), Chennai -600051, Tamil Nadu, India

\section{CONFLICTS OF INTEREST}

The authors declare that they have no conflicts of interest.

\section{REFERENCES}

Abebe.A.B. Anagaw; Yazie, Biruk (2019). Determinants of women's participation in agricultural extension services among rural women farmers in Yilmanadensa District, Northwest Ethiopia. J. of Agril. Ext. Mangt., 20 (1) :1-18

Anithakumari. P.; Mahima, Mohan and Muralidharan, K. (2021). Impact of training programs for women farmer groups under the farmer FIRST program. Indian Res. J. Ext. Edu., 21 (2\&3) : 8-15.

Atsbeha, A.T.; Gebre, G.G. and Lu, Z. (2021). Factors affecting women access to agricultural extension services: evidence from poultry producer women's in North western Tigray, Ethiopia. Cogent Social Sci., 7(1) : 20-21.

Berhane, G.; Ragasa, C.; Abate, G.T. and Assefa, T.W. (2018). The state of agricultural extension services in Ethiopia and their contribution to agricultural productivity. ESSP working paper 2018, International Food Policy Research Institute, Rome.

Bashir, Bimal; Thirupathy, P.; Venkatachalapathy, R.; Jamuna, Valsalan and Rout, P.K. (2017). Impact of Trainings on Knowledge Level of Goat Keepers and New Entrepreneurs in Kerala. Indian Res. J. Ext. Edu., 17 (1) : 67-70.

Chander, M.; Dutt, T.; Ravikumar, R.K and Subrahmanyeswari, B. (2010). Livestock technology transfer services in India: A review, Indian J. of Animal Sci., 80 (11) : 59-69.

Dethier, J-J and Effenberger, A. (2012). Agriculture and development: Abrief review of the literature. Eco. Systems, 36 (2) : $175-205$.

Government of Tamil Nadu Policy note (2021 - 2022) (Demand No.6). Department of Animal Husbandry, Dairying, Fisheries and Fishermen Welfare. Tamil Nadu

Jothilakshmi, M.D.; Thirunavukkarasu and Sudeepkumar, N.K. (2011). Structural changes in livestock service delivery system: A case study of India. Asian J.of Agril. Res. 5 : 98-108. 
Jothilakshmi, M.; Thirunavukkarasu, D. and N.K. Sudeepkumar (2014). Exit of youths and feminization of smallholder livestock production-a field study in India. Renewable Agriculture and Food Systems, 29, pp 146-150.

Krishna, V.V.; Arvalath, L.M. and Vikraman, S. (2019). Does caste determine farmer access to quality information? Plos One 14(1):e0210721. DOI: http://doi.org/10.1371/10.1371/journal.pone.0210721.

Livestock Census (2012). All India report of the Government of India, Ministry of Agriculture, Department of Animal Husbandry, Dairying and Fisheries, Krishi Bhawan, New Delhi

Mamun-ur-Rashid; Kamruzzaman, M. and Emad Mustaf (2017). Women participation in agricultural extension services in Bangladesh: Current status, prospects and challenges. Bangladesh J. of Ext. Edu., 29 (1\&2) : 93-107

Nandi, R and Nedumaran, S.S. (2019). Agriculture extension system in India: A meta-analysis. Res. J. of Agril. Sci., 10 (3) : $473-479$

Narmatha, N, V.; Uma, L. Arun and R. Geetha (2009). Level of participation of women in livestock farming activities. Tamil Nadu J. of Vet.and Animal Sci., 5 (1) : 4-8

Prasad, H.N. and Kushwaha, R.K. (2015). Impact of KVK's training programmes on socio-economic status of farm women. Plant Archives, 15 (1) : 421-428

Raghunathan, K.; Kannan, S. and Qui. (2018). Women's self-help groups, decision-making, and improved agricultural practices in India: from extension to practice, IFPRI Discussion Paper 010031735. Washington, DC: International Food Policy Research Institute (IFPRI), Rome.

Ravikumar, R.K. and Chander, M. (2006). Extension education efforts by state department of animal husbandry (SDAH), Tamil Nadu SWOT Analysis. Livestock Res. for Rural Devel. 18 (9).

Safia, N.E. and Girija, Devi. V. (2021). Factors influencing entrepreneurial behavior of women participants in vocational training by krishi vigyan kendra. Indian Res. J. Ext. Edu., 21 (4) : 53-55

Thirunavukkarasu, D.; Narmatha, N.; Doraisamy, K.A.; Ramesh, V.; Saravanakumar and Sakthivel, K.M. (2019). Future prospects of smallholder dairy production: Pragmatic evidence from crop-livestock farming systems of an economically transforming state in India. Cuadernos de Desarrollo Rural, 16(84).https://doi.org/10.11144/Javeriana.cdr16-84.fpsd

Thirunavukkarasu,D.; Narmatha, N. and Alagudurai, S. (2021). What drives the adoption of fodder innovation(s) in a smallholder dairy production system? Evidence from a cross-sectional study of dairy farmers in India. 371. Tropical GrasslandsForrajes Tropicales, 9 (3) : 371-375 DOI: 10.17138/TGFT (9)371-375. 